\title{
RESPONSE OF THE GROWTH PLATES TO TIBIAL OSTEOTOMY IN RATS
}

\author{
JOHN F. TAYLOR, ELIZABETH WARRELL, RONALD A. EVANS
}

\begin{abstract}
From the Department of Orthopaedics, Liverpool University, and the Alder Hey Children's Hospital, Liverpool
\end{abstract}
\begin{abstract}
The parameters of cellular proliferation and growth in the growth plates of immature rats were measured after unilateral tibial osteotomy and used to calculate growth rates.

Distal osteotomy of one tibia was followed by a bilateral increase in the calculated growth rate of the distal growth plates. However, the ipsilateral distal growth plate grew faster than the contralateral between 12 and 18 days after operation, which appeared to be related to increased cell proliferation and height. Proximal osteotomy led to an increase in growth rates proximally which was more marked on the contralateral side. The lesser response of the ipsilateral growth plate may have been due to local impairment of blood supply, or to greater local release of metabolites after bony damage.

Distal tibial osteotomy gave similar results to circumferential release of the distal tibial periosteum. Proximal osteotomy, however, produced a relative impairment of growth on the operated side. This may be of importance in the correction of childhood deformities associated with inequality of leg length.
\end{abstract}

A diaphyseal fracture is probably the commonest cause of shortening of a limb (Hansson 1967). If the bone ends overlap there is immediate shortening, but in a child more rapid ipsilateral growth may equalise limb length in the subsequent two years. This growth stimulation has been attributed to trauma to the cortex (Bertrand and Trillat 1948), or to associated effects of the fracture such as obliteration of the medullary cavity (Wray and Lynch 1959).

Crilly (1972) produced evidence that circumferential periosteal division alone was followed by overgrowth of the radius in the immature chicken. The operation appeared to have the greatest effect on the more distant growth plate, and a similar effect was noted by Hansson (1967) after medullary plugging. However, the effect on the contralateral limb is uncertain. Levander (1929) found growth promotion in bones other than in the injured limb, but Wray and Goodman (1961) reported an initial bilateral slowing of growth after tibial fracture in rats as compared to normal controls. The inhibition was

J. F. Taylor, MD, MCh Orth, Consultant Orthopaedic Surgeon Alder Hey Children's Hospital, Eaton Road, Liverpool L12 2AP, England.

E. Warrell, PhD

Department of Orthopaedics, Liverpool University, PO Box 169, Liverpool L39 3BX, England.

R. A. Evans, MCh Orth, Orthopaedic Registrar

Walton Hospital, Rice Lane, Liverpool L9 1 AE, England.

(C) 1987 British Editorial Society of Bone and Joint Surgery $0301-620 \mathrm{X} / 87 / 4136 \$ 2.00$ less marked on the side of the fracture, thus permitting overgrowth on the injured side.

In a recent study of the effects of circumferential periosteal division in rats (Taylor, Warrell and Evans 1987) calculation of growth rate from histological data led us to conclude that periosteal release was associated with a specific unilateral growth stimulus and that the bilateral effect was part of the systemic response to trauma. However, unlike Crilly (1972) and Hansson (1967) we found a significant increase only at the growth plate adjacent to the periosteal division.

We have now studied the effect of proximal and of distal unilateral tibial osteotomy on the growth plates of the immature rat in order to compare the nature and magnitude of the response in the tibial growth plates with those found after periosteal release alone.

\section{MATERIAL AND METHODS}

We calculated growth rates from the number and size of cells in the growth plate at various stages. Male Wistar rats aged 28 days were randomly assigned to the control group, or to the two experimental groups having an osteotomy either in the upper or lower tibia. Control animals were anaesthetised with intraperitoneal pentobarbitone sodium (Nembutal) and then allowed to recover. Experimental animals had the same anaesthetic and then the skin of the left leg was cleaned with aqueous chlorhexidine gluconate. Proximal or distal osteotomies were undertaken through $10 \mathrm{~mm}$ anterior skin incisions, 
the metaphysis being divided with an ampoule saw, $3 \mathrm{~mm}$ from the growth plate.

Rats were killed in pairs on the first and third postoperative days (at 29 and 31 days of age) and at three-day intervals to 46 days of age. The results from 28 day-old control rats were matched with those from 29day-old experimental animals. One hour prior to death, between $10 \mathrm{a} . \mathrm{m}$. and $12 \mathrm{a} . \mathrm{m}$., the rats were given $1 \mu \mathrm{Ci} / \mathrm{g}$ body weight of tritiated thymidine (Radiochemical Centre, Amersham, $5 \mathrm{Ci} / \mathrm{mmol}$ ). All the animals were killed with chloroform, their tibiae excised, fixed with $10 \%$ formalin in $0.9 \%$ saline, and decalcified in $20 \%$ sodium citrate and $80 \%$ formic acid. The bones were embedded in paraffin wax and sections $5 \mu \mathrm{m}$ thick were cut. They were coated with Kodak AR 10 stripping film and exposed at $4^{\circ} \mathrm{C}$ for five weeks. The film was then developed and the sections stained with Ehrlich's haematoxylin and eosin.

Labelling index. Three labelled sections were examined for each growth plate and measurements were made of the chondrocytes in at least 100 cell columns in the central two-thirds of each plate. The position of each cell was determined by counting from cell position 1 at the epiphyseal end towards the metaphysis, and cellular enlargement used to define the first hypertrophic cell (Fig. 1). On a chart of each growth plate, symbols were

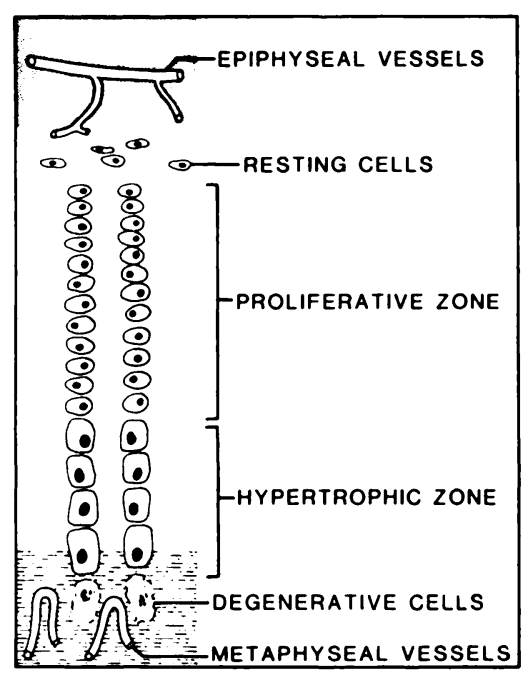

Fig. 1

Diagram of growth plate to show the measured parameters.

used to distinguish nucleated cells and whether the nucleus was "labelled" with more than 10 photographic grains per nucleus. The labelling index (LI) was calculated as the percentage of labelled, nucleated cells in the proliferative zone.

Diurnal variation in the rodent chondrocyte labelling index has been described by Walker and Kember (1972). The animals in our study were killed between 11 a.m. and 1.0 p.m. at a time when the labelling index may be slightly lower than the mean, but there is unlikely to be a notable error as these authors have shown that diurnal variation is masked by experimental error.

The proliferative zone. We defined this zone as that which contained cells without notable enlargement. We thus identified two zones in each cell column: the proliferative and the hypertrophic. This allowed correlation of the number of cells in each zone, and the height of the zone (measured in the long axis of the bone) with the labelling index and with the calculated growth rate. Kember (1972) noted broadly similar labelling profiles in different growth plates and gave good reasons for determining an "effective" proliferative zone on the basis of labelled cells alone. However, our preliminary studies showed differing profiles at proximal and distal growth plates. Moreover, to have used Kember's method would have necessitated the definition of a transitional zone between the "effective" proliferative and the hypertrophic zones, which would consist of unlabelled cells without notable enlargement. The mean position for the lowest cell in a minimum of 100 proliferative zones was used to calculate the mean number of cells in the proliferative columns. Hypertrophic cells. The heights of the lowest intact hypertrophic cells were measured in the long axis of the bone using an eyepiece graticule. The number of cells per column and the height of the column were measured from the first enlarged cell to the lowest intact cell above the line of vascular erosion.

Calculated growth rate. The labelling index (LI) represents the percentage of cells seen to be synthesising DNA, and therefore in the $S$ phase of mitosis. The duration of the $S$ phase for growth cartilage cells of the tibia of a six-week-old rat is seven hours.

Therefore, in a cartilage column, each 24 hours

$$
\begin{gathered}
\text { The mean number of cells } \\
\text { synthesising DNA }
\end{gathered}=\frac{\mathrm{LI}}{100} \times \frac{\text { the number of cells in }}{\text { the proliferative zone }} \times \frac{24}{7}
$$

If all cells going through the $S$ phase subsequently divide then this is also the rate of cell production (RCP). The growth rate has therefore been calculated by multiplying the RCP by the average height of the hypertrophic cells.

\section{RESULTS}

The histological measurements on growth plates from control animals generally had neither an upward nor a downward trend during the period of observation, but the combined results from both left and right proximal plates did reveal a significant diminution with time in the height of the hypertrophic zone $(t=2.8, \mathrm{p}<0.02)$ as a consequence of ageing. In the distal growth plate there was a significant diminution of hypertrophic cell height $(t=2.02, \mathrm{p}<0.05)$. There was no significant difference in the mean values between left and right leg.

The percentages of labelled cells was greatest in those cells occupying positions 4 to 7 in the proliferative 
Table I. Comparison of the proximal and distal growth plates of rats in the period 0 to 18 days after proximal tibial osteotomy of the left tibia

\begin{tabular}{|c|c|c|c|c|c|c|}
\hline & \multicolumn{3}{|c|}{ Proximal growth plate } & \multicolumn{3}{|c|}{ Distal growth plate } \\
\hline & \multirow{2}{*}{$\begin{array}{l}\text { Control rats } \\
\text { Both lezes }\end{array}$} & \multicolumn{2}{|c|}{ Experimental rats } & \multirow{2}{*}{$\begin{array}{l}\text { Control rats } \\
\text { Both legs }\end{array}$} & \multicolumn{2}{|c|}{ Experimental rats } \\
\hline & & Left les & Right leg & & Left leg & Right leq \\
\hline $\begin{array}{l}\text { Calculated growth rate } \\
(\mu \mathrm{m} / \text { day })\end{array}$ & $296 \pm 89^{* *}$ & $340 \pm 73$ & $381 \pm 105 * \ddagger$ & $73 \pm 28^{* *}$ & $118 \pm 43^{*}$ & $121 \pm 60^{*}$ \\
\hline Labelling index & $10.8 \pm 2.9$ & $11.8 \pm 2.4$ & $11.7 \pm 2.9$ & $7.5 \pm 1.9$ & $9.0 \pm 2.4$ & $9.1 \pm 2.9$ \\
\hline $\begin{array}{l}\text { Proliferative cells/column } \\
\text { zone height }(\mu \mathrm{m})\end{array}$ & $\begin{array}{l}22.5 \pm 2.4 \\
275 \pm 24^{* * *}\end{array}$ & $\begin{array}{l}22.4 \pm 2.4 \\
271 \pm 30\end{array}$ & $\begin{array}{l}25.0 \pm 2.5^{*} \dagger \\
302 \pm 23^{*} t\end{array}$ & $\begin{array}{l}10.1 \pm 0.8^{* *} \\
137 \pm 9.8\end{array}$ & $\begin{array}{l}12.3 \pm 1.9^{*} \\
157 \pm 30^{*}\end{array}$ & $\begin{array}{l}12.7 \pm 1.7^{*} \\
145 \pm 16\end{array}$ \\
\hline $\begin{array}{l}\text { Hypertrophic cells/column } \\
\text { zone height }(\mu \mathrm{m}) \\
\text { cell height }(\mu \mathrm{m})\end{array}$ & $\begin{array}{l}5.8 \pm 0.4 \\
165 \pm 25 \\
35.7 \pm 2.2^{* *}\end{array}$ & $\begin{array}{c}5.7 \pm 1.3 \\
173 \pm 41 \\
37.5 \pm 3.1\end{array}$ & $\begin{array}{c}7.0 \pm 1.1^{*}+ \\
220 \pm 39^{*}+ \\
38 \pm 2.6^{*}\end{array}$ & $\begin{array}{l}4.0 \pm 0.3^{* *} \\
73 \pm 8.5 \\
27.9 \pm 2.8\end{array}$ & $\begin{array}{r}3.4 \pm 0.6^{*} \\
88 \pm 21^{*} \\
31.2 \pm 4.6^{*}\end{array}$ & $\begin{array}{l}3.2 \pm 0.3 \\
72 \pm 11 \\
29 \pm 4.2\end{array}$ \\
\hline Growth plate height $(\mu m)$ & $440 \pm 37^{* *}$ & $444 \pm 68$ & $523 \pm 54^{*}+$ & $211 \pm 15.6$ & $245 \pm 50.4^{*}$ & $220 \pm 25.7$ \\
\hline Number of rats & 22 & 11 & 12 & 12 & 12 & 10 \\
\hline
\end{tabular}

The tables give the mean and standard deviation for each parameter.

- Student's $t$-test reveals a difference $p<0.05$ between the values from left or right leg of the experimental animal and the mean figure for the control animals.

* Student's $t$-test reveals a difference $p<0.05$ between control figures and the experimental figures from left and right legs together.

+ Student's $t$-test reveals a difference $p<0.05$ between the ipsilateral and the contralateral legs of the experimental animal.

$\$$ Probability $p<0.05$ when the results for a selected period were compared with those for the contralateral leg of the experimental animal (Wilcoxon's signed-rank test).

column of the proximal growth plate and in positions 1 to 3 in the distal growth plate.

Proximal osteotomy (Table I and Fig. 2)

Proximal growth plate. With the exception of the labelling index (LI) the mean values of all measurements were significantly increased in the proximal growth plate of the contralateral (right) leg of experimental animals as compared to the unoperated controls (Table I). This was not the case in the leg which had been osteotomised; here the measured values were similar to those of control animals. There was thus a significant increase in the numbers of proliferative and hypertrophic cells in the contralateral proximal growth plate as compared to the side subjected to operation.

The pattern of change after osteotomy varied with the parameter studied (Fig. 2). The proximal growth plates of control rats showed no change of growth rate with time but the contralateral proximal growth plates of experimental animals showed an increase of growth rate significantly above control values $(t=2.23, \mathrm{p}<0.05)$. The labelling index in the proximal growth plate of both right and left legs of the experimental animals was below control values one day after operation, and rose to well above it by the ninth day, subsequently falling. The height of the hypertrophic cells was relatively constant throughout.

Distal growth plate. In the distal growth plate after proximal osteotomy we found a bilateral increase in the mean number of cells in each proliferative cell column when compared to normal controls $(t=4.4, \mathrm{p}<0.001)$.

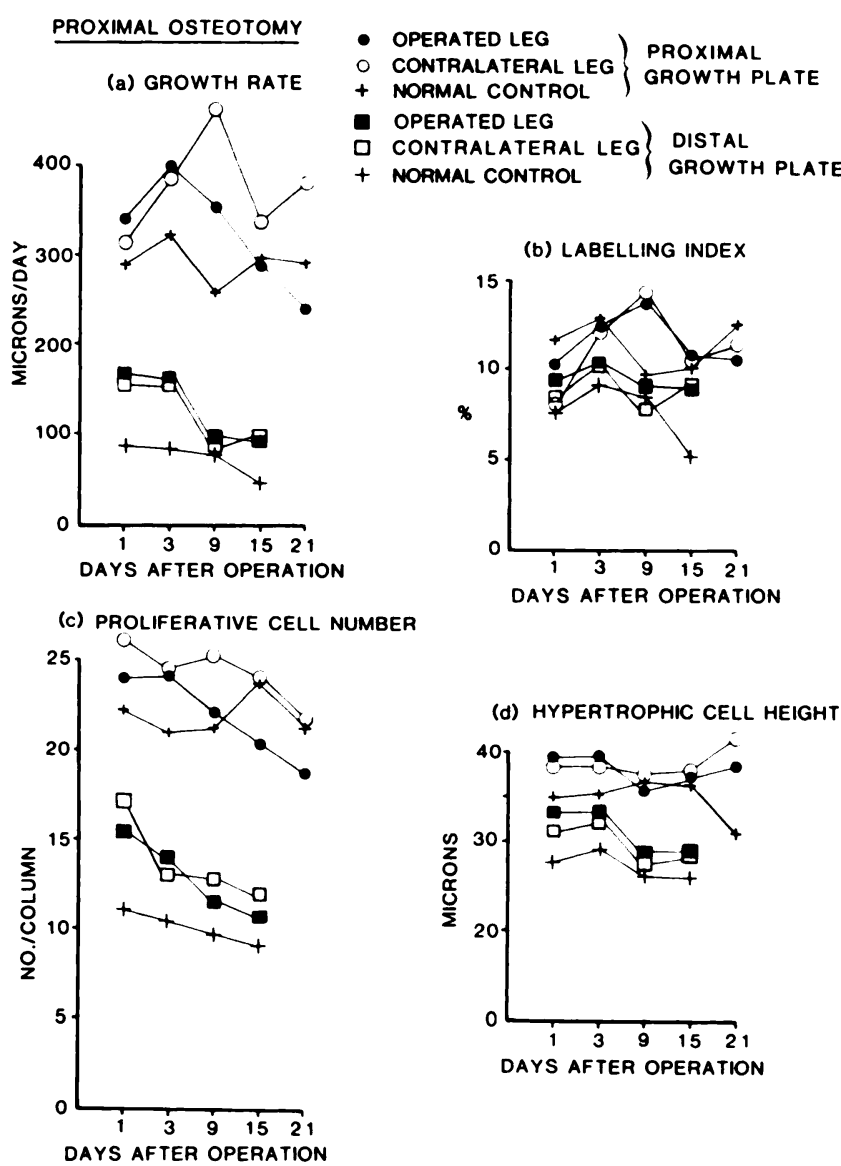

Fig. 2

Results after proximal osteotomy. 
Table II. Comparison of the proximal and distal growth plates of rats in the period 0 to 18 days after distal tibial osteotomy of the left tibia

\begin{tabular}{|c|c|c|c|c|c|c|}
\hline & \multicolumn{3}{|c|}{ Proximal growth plate } & \multicolumn{3}{|c|}{ Diatal growth plate } \\
\hline & \multirow{2}{*}{$\begin{array}{l}\text { Control rats } \\
\text { Both lews }\end{array}$} & \multicolumn{2}{|c|}{ Experimeatal rats } & \multirow{2}{*}{$\begin{array}{l}\text { Control rats } \\
\text { Both leos }\end{array}$} & \multicolumn{2}{|c|}{ Experimental rats } \\
\hline & & Left leg & Right les & & Left leg & Right leg \\
\hline $\begin{array}{l}\text { Calculated growth rate } \\
(\mu \mathrm{m} / \text { day })\end{array}$ & $296 \pm 89$ & $353 \pm 124 \ddagger$ & $342 \pm 85$ & $73 \pm 28 * *$ & $128 \pm 63^{*}$ & $111 \pm 52 * t$ \\
\hline Labelling index & $10.8 \pm 2.9$ & $12.1 \pm 3.3 \ddagger$ & $11.4 \pm 2.5$ & $7.5 \pm 2.0$ & $9.6 \pm 3.4$ & $8.5 \pm 2.8$ \\
\hline $\begin{array}{l}\text { Proliferative cells/column } \\
\text { zone height }(\mu \mathrm{m})\end{array}$ & $\begin{array}{l}22.5 \pm 2.4 \\
275 \pm 24^{* *}\end{array}$ & $\begin{array}{l}22.3 \pm 2.6 \\
293 \pm 28^{*}\end{array}$ & $\begin{array}{c}23.1 \pm 2.1 \\
292 \pm 22\end{array}$ & $\begin{array}{l}10.1 \pm 0.8 * * \\
137 \pm 10\end{array}$ & $\begin{array}{l}12.1 \pm 2.3^{*} \\
148 \pm 25^{*}\end{array}$ & $\begin{array}{l}12.1 \pm 2.2^{*} \\
154 \pm 23^{*}\end{array}$ \\
\hline $\begin{array}{l}\text { Hypertrophic cells/column } \\
\text { zone height }(\mu \mathrm{m}) \\
\text { cell height }(\mu \mathrm{m})\end{array}$ & $\begin{array}{r}5.8 \pm 0.4 * * \\
165 \pm 40^{* *} \\
35.7 \pm 2.2^{* *}\end{array}$ & $\begin{array}{l}6.6 \pm 0.8^{*} \\
200 \pm 21 \\
38.2 \pm 2.0^{*}\end{array}$ & $\begin{array}{l}6.8 \pm 0.8^{*} \\
196 \pm 22 \\
37.5 \pm 1.7^{*}\end{array}$ & $\begin{array}{c}4.0 \pm 0.3 \\
73 \pm 39 \\
27.9 \pm 2.8 * *\end{array}$ & $\begin{array}{l}4.4 \pm 1.5 \\
106 \pm 8.5 \dagger \\
31.8 \pm 3.7\end{array}$ & $\begin{array}{c}3.8 \pm 0.7 \\
86 \pm 20^{*} \\
30.8 \pm 3^{*}\end{array}$ \\
\hline Growth plate height $(\mu m)$ & $440 \pm 37 * *$ & $490 \pm 15^{*}$ & $488 \pm 17^{*}$ & $211 \pm 15.6$ & $253 \pm 81$ & $243 \pm 39^{*}$ \\
\hline Number of rats & 22 & 17 & 14 & 12 & 15 & 15 \\
\hline
\end{tabular}

For key, see footnote to Table 1 (facing).

With this exception the significant increases were found to be on the operated side, including the height of the proliferative zone, the number and height of the
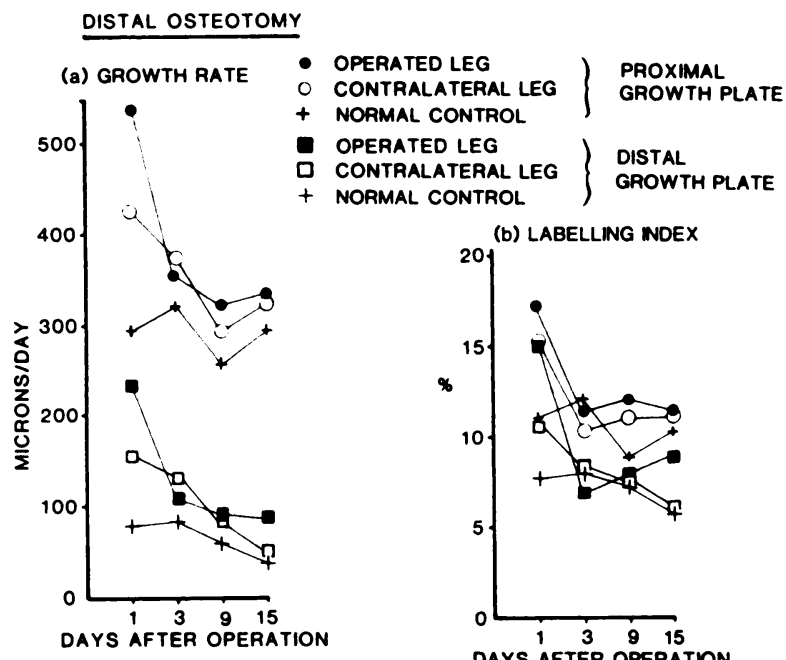

Normal CONTROL

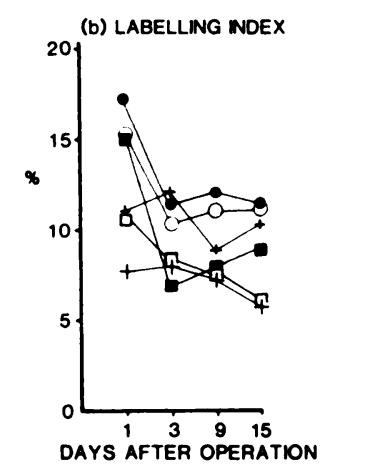

(c) PROLIFERATIVE CELL NUMBER
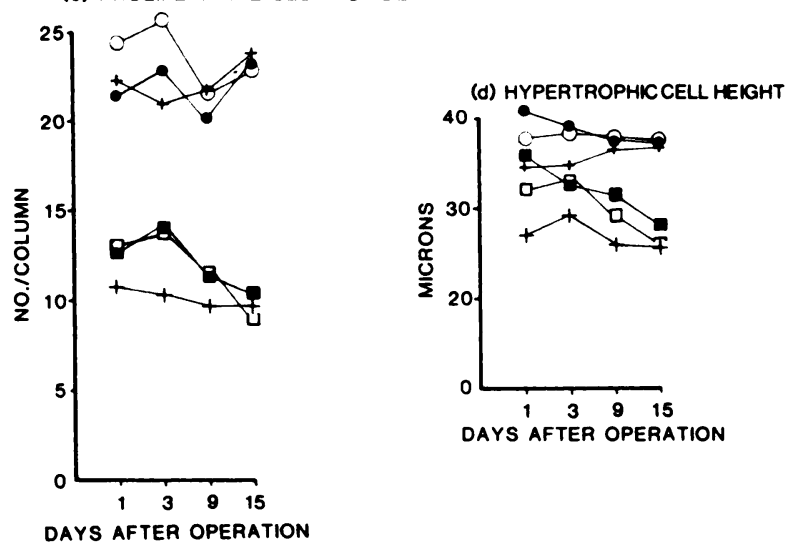

Fig. 3

Results after distal osteotomy. hypertrophic cells, and the heights of the hypertrophic zone and the growth plate. However, calculation of growth rates revealed a significant increase on both sides as compared to controls. None of the values were significantly different between the left and the right leg of the experimental animals (Table I).

The distribution of labelling in the distal growth plate changed after proximal osteotomy. Before operation the greatest percentage of labelled cells was seen in the cells 1 to 3 as numbered from the epiphyseal end. After osteotomy $41 \%$ of growth plates had the greatest percentages of labelling in positions 4 to 7 , that is further from the epiphysis.

Distal tibial osteotomy (Table II and Fig. 3)

Proximal growth plate. After distal osteotomy the mean number of hypertrophic cells and height of the growth plate were increased in both left and right proximal growth plates. The mean values of these parameters after proximal or distal tibial osteotomy (Tables I and II) were comparable in the contralateral leg, but in the osteotomised tibia these values were lower after proximal than distal osteotomy.

Figure 3 reveals that unlike the findings immediately after proximal osteotomy, the labelling index was initially above normal control values. After a fall at three days, a relative increase is seen on both sides at nine and 15 days. No significant difference could be demonstrated between the mean labelling index of the proximal growth plates of the left and right legs throughout the period of observation, but only in the period 3 to 15 days after operation $(p<0.01$, Wilcoxon matched pairs signed-rank test).

The mean growth rate was significantly increased on the operated side as compared to the opposite side in the period 6 to 15 days after operation $(\mathrm{p}<0.05$, Wilcoxon's signed-rank test). 
In the proximal growth plate on the operated side, multiple regression analysis showed that of all the parameters the labelling index correlated most closely with the calculated growth rate $(t=4.86, \mathrm{p}<0.0001)$. Distal growth plate. At the distal growth plates after distal osteotomy the mean number of proliferative cells was raised equally on both sides as compared to control values, with an associated increase in the height of the proliferative zone. The mean height of the hypertrophic cells was also bilaterally increased. The increase in the height of the hypertrophic zone was significantly greater on the operated, as compared to the contralateral leg. The mean labelling index was raised, but not significantly so, in both legs. On the operated side the distribution of labelling in the distal growth plate had changed so that $28 \%$ of growth plates had the greatest percentage labelling in cell positions 4 to 7 in the proliferative columns.

Calculations of growth rates revealed a bilateral increase as compared to control animals, that on the operated side being the greater. The difference between left and right in operated animals was significant in the period 12 to 18 days after operation $(p<0.05$ Wilcoxon signed-rank test). overgrowth, but no change in rate of growth at the proximal end. However, Brodin (1955), who performed a proximal tibial periosteal release in rabbits, also noted a diminished proximal rate of growth but an increase distally. This operation reproduces one feature of a displaced fracture. Proximal operative procedures thus appear to diminish ipsilateral overgrowth.

We found that the proximal growth rate does rise after proximal osteotomy, being greatest some days after operation. Wray and Goodman (1961) found an initial bilateral retardation of femoral growth after fracture of the tibiae in rats. They considered that this might be due to the metabolic response to trauma or to relative immobility soon after operation. However, the relatively low ipsilateral proximal growth rate after proximal osteotomy leads us to conclude that vascular changes associated with the osteotomy may be responsible for this unilateral failure to respond to a systemic growth stimulus. At the contralateral proximal growth plate there is an increase in the mean number of proliferative cells and in the height and number of hypertrophic cells as compared to control animals.

After distal osteotomy the recorded distal growth rates on both sides were significantly greater than in

Table III. Mean calculated growth rates for the period 0 to 18 days after distal periosteal release or proximal or distal osteotomy of the left tibia in the rat. Combined figures for both the proximal and the distal growth plates (in micrometers)

\begin{tabular}{|c|c|c|c|c|c|c|c|}
\hline & \multirow{2}{*}{$\begin{array}{l}\text { Combined } \\
\text { left and } \\
\text { right } \\
\text { control legs }\end{array}$} & \multicolumn{2}{|c|}{$\begin{array}{l}\text { Distal } \\
\text { periosteal release* }\end{array}$} & \multicolumn{2}{|c|}{ Proximal osteotomy } & \multicolumn{2}{|c|}{ Diatal osteotomy } \\
\hline & & Left & Right & Left & Right & Left & Right \\
\hline Mean calculated growth rate & 369 & 451 & 430 & 458 & 502 & 481 & 453 \\
\hline $\begin{array}{l}\text { Difference between tibiae of } \\
\text { experimental animals and normal controls }\end{array}$ & & 82 & 61 & 89 & 133 & 112 & 84 \\
\hline $\begin{array}{l}\text { Difference between left and right } \\
\text { legs of experimental animals }\end{array}$ & & 21 & & -44 & & 28 & \\
\hline
\end{tabular}

- Figures from Taylor, Warrell and Evans 1987.

\section{DISCUSSION}

Calculation of the mean growth rates after proximal tibial osteotomy has shown that there is a bilateral increase at both proximal and distal growth plates as compared to that in control animals. However, at the proximal growth plate in the operated leg the increase was small and not significant. A much larger increase was found on the contralateral side.

The relatively low growth rates recorded in the proximal growth plate of the same tibia after proximal osteotomy may be due to the broad area of bone contact, which prevents displacement and consequent shortening. Hedström (1969) noted increased growth in humeral fractures which were displaced. McCormick, Lowe and Ashworth (1972) found a similar effect on growth rate after a Type 1 epiphyseal fractures through the right upper tibial growth plate of immature rabbits, with distal control animals. There was also a significant increase in the ipsilateral distal growth rate as compared to the opposite side in the period 12 to 18 days after operation. This unilateral increase in distal growth rate is associated with a bilateral increase in the height of the hypertrophic cells and the height of the proliferative zone at both growth plates. There was no significant difference between the growth rates of the proximal growth plates after distal tibial osteotomy. Our study of periosteal release (Taylor et al. 1987) led us to conclude that the effect of diminished periosteal tension was reflected mainly in an increase in the rate of cell proliferation. It is clear that both proximal and distal osteotomy are associated with a bilateral stimulus to hypertrophic cell height.

Kember (1972) found that all of the parameters contributing to growth rate varied in the different growth 
plates in one animal, and our results support this concept. We are in agreement with Seinsheimer and Sledge (1981) that the labelling index is a most useful index of chondrocyte activity. There was close correlation between the labelling index and growth rate at the proximal growth plate after distal osteotomy; but this trend was not demonstrated at the distal growth plate because of the small sample size.

This study emphasises the complex control of the growth plate. Rigal (1962) proposed that division in each cell column is synchronous, but we did not observe this. Trueta (1962) suggested that the position of chondrocytes in relation to their blood supply is important in determining activity, and this concept is supported by the work of Brighton (1978). In the control rats of the present study maximum labelling was noted at the top of the cell columns in the distal growth plate. However, osteotomy might be expected to lead to an epiphyseal hyperaemia, and in histological studies after osteotomy the labelling index was greatest a few cells deep to the top of the column. Moss-Salentijn (1974) has emphasised that extrinsic factors may modify growth plate activity. However, the magnitude of the responses to osteotomy at proximal and distal growth plates leads us to conclude that intrinsic genetic information and cellular communication play a major role in determining chondrocyte activity.
The calculated growth rates from both the proximal and distal growth plates have been combined in Table III. We have also included information from operations undertaken with an exactly similar method, but in which the distal tibial periosteum was divided circumferentially (Taylor et al. 1987). Distal tibial osteotomy and periosteal division both lead to a bilateral increase in tibial growth rate, greater on the ipsilateral side. However, after proximal osteotomy the growth rate in the same leg is similar to that seen after the other operations, but it is greatly increased in the contralateral leg. If similar differences follow corrective upper tibial osteotomy in children with a deformed and short leg, then the operation may lead to an increase in the discrepancy of length. Moreover, displacement and overlap of fragments is more likely in distal than in proximal tibial fractures. Our study supports the clinical observation (Compere and Adams 1937) that growth stimulus is proportional to the extent of overlap.

This work was supported by grant No. 352 from Liverpool Area Health Authority Research Committee. We are grateful for the support of Professor R. Roaf, advice from Professors G. Bentley and G. Burwell, $\operatorname{Dr}$ N. F. Kember and Dr R. G. Crilly, and statistical assistance from Dr C. Osmond and Miss S. Macfarlane. Technical expertise was provided by $\mathrm{Mr} \mathrm{A}$. Taunton and Mrs $\mathrm{C}$. Oliver and photographs by $\mathrm{Mr}$ C. Fitzsimmons.

\section{REFERENCES}

Bertrand $\mathbf{P}$, Trillat $\mathbf{S}$. Le traitement des inégalités de longueur des membres inférieurs pendant la croissance. Rev Orthop $1948 ; 34: 264-311$.

Brighton CT. Structure and function of the growth plate. Clin Orthop $1978 ; 136: 22-32$.

Brodin H. Longitudinal bone growth. The nutrition of the epiphyseal cartilages and the local blood supply: an experimental study in the rabbit. Acta Orthop Scand 1955; Suppl 20.

Compere EL, Adams CO. Studies of longitudinal growth of long bones. 1. The influence of trauma to the diaphysis. J Bone Joint Surg 1937;19:922-36.

Crilly RG. Longitudinal overgrowth of chicken radius. $J$ Anat 1972;112:11-8.

Hansson LI. Daily growth in length of diaphysis measured by oxytetracycline in rabbit normally and after medullary plugging. Acta Orthop Scand 1967; Suppl 101.

Hedströ $\mathrm{m}$. Growth stimulation of long bones after fracture or similar trauma: a clinical and experimental study. Acta Orthop Scand 1969; Suppl 122.

Kember NF. Comparative patterns of cell division in epiphyseal cartilage plates in the rat. $J$ Anat 1972;111:137-42.

Levander G. Über die Behandlung von Brüchen des Oberschenkelschaftes; nebst Beitrag sur Kenntnis des gesteigerten Längenwachstums der Rohrenknochen der unteren Extremitaten nach Bruch derselben. Acta Chir Scand 1929;65 Suppl 12:5-237.

McCormick MJ, Lowe PJ, Ashworth MA. Analysis of the relative contributions of the proximal and distal epiphyseal plates to the growth in length of the tibia in the New Zealand white rabbit. Growth 1972;36:133-44.

Moss-Salentijn L. Studies of long bone growth. 1. Determination of differential elongation in paired growth plates of the rat. Acta Anat $1974 ; 90: 145-60$.

Rigal WM. The use of tritiated thymidine in studies of chondrogenesis. In: McLean FC, Lacroix P, Budy AM. eds. Radioisotopes and bone: a symposium organized by the Council for International Organizations of Medical Sciences. Oxford: Blackwell Scientific Publications, 1962:197-225.

Seinsheimer F III, Sledge CB. Parameters of longitudinal growth rate in rabbit epiphyseal growth plates. J Bone Joint Surg [Am] $1981 ; 63-A: 627-30$.

Taylor JF, Warrell E, Evans RE. The response of rat tibial growth plates to distal periosteal division. J Anat 1987;151:221-31.

Trueta J. The vascular rôle in calcification and osteogenesis. In: McLean FC, Lacroix P, Budy AM, eds. Radioisotopes and bone: $a$ symposium organized by the Council for International Organizations of Medical Sciences. Oxford: Blackwell Scientific Publications, 1962:371-91.

Walker KV, Kember NF. Cell kinetics of growth in the rat tibia. I. Measurements in young male rats. Cell Tissue Kinet 1972;5:401-8.

Wray JB, Goodman HO. Post-fracture vascular phenomena and longbone overgrowth in the immature skeleton of the rat. J Bone Joint Surg [Am] $1961 ; 43-A: 1047-55$.

Wray JB, Lynch CJ. The vascular response to fracture of the tibia in the rat. J Bone Joint Surg [Am] 1959;41-A:1143-8. 